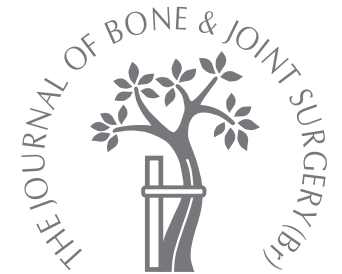

D. P. Forward,

T. R. C. Davis, J. S. Sithole

From Nottingham University Hospitals, Nottingham, England
D. P. Forward, MA, FRCS DM, Specialist Registrar T. R. C. Davis, FRCS, MCh, Special Professor in Trauma and Orthopaedic Surgery Department of Trauma and Orthopaedic Surgery J. S. Sithole, MSc, PhD, Lecturer in Medical Statistics Trent Research \& Development Support Unit Nottingham University Hospitals, Queen's Medical Centre Campus, Nottingham NG7 2UH, UK.

Correspondence should be sent to Mr. D. P. Forward; e-mail: daren.forward@virgin.net

(C)2008 British Editorial Society of Bone and Joint Surgery doi:10.1302/0301-620X.90B5 $19448 \$ 2.00$

$J$ Bone Joint Surg $[\mathrm{Br}]$ 2008;90-B:629-37. Received 15 March 2007; Accepted after revision 20 December 2007

\title{
Do young patients with malunited fractures of the distal radius inevitably develop symptomatic post-traumatic osteoarthritis?
}

Fractures of the distal radius occurring in young adults are treated increasingly by open surgical techniques, partly because of concern that failure to restore the alignment of the fracture accurately may cause symptomatic post-traumatic osteoarthritis in future years. We reviewed 106 adults who had sustained a fracture of the distal radius between 1960 and 1968 and who were below the age of 40 years at the time of injury. We carried out a clinical and radiological assessment at a mean follow-up of 38 years (33 to 42 ).

No patient had required a salvage procedure. While there was radiological evidence of post-traumatic osteoarthritis after an intra-articular fracture in $68 \%$ of patients (27 of 40), the disabilities of the arm, shoulder and hand (DASH) scores were not different from population norms, and function, as assessed by the Patient Evaluation Measure, was impaired by less than $10 \%$. Ordinal logistic regression analysis showed a significant relationship between narrowing of the joint space and extra-articular malunion (dorsal angulation and radial shortening) as well as intra-articular injury. Multivariate analysis revealed that grip strength had fallen to $89 \%$ of that of the uninjured side in the presence of dorsal malunion, but no measure of extra-articular malunion was significantly related to either the Patient Evaluation Measure or DASH scores.

While anatomical reduction is the principal aim of treatment, imperfect reduction of these fractures may not result in symptomatic arthritis in the long term, and this should be considered when counselling patients on the risks and benefits of the many treatment options available.

Malunion is common after treatment of fractures of the distal radius by closed reduction and immobilisation in plaster. $^{1}$ There is increasing concern that failure to restore accurate extraarticular alignment may result in persistent pain, restricted movement of the wrist and forearm and weakness and disability due to malfunction of the radiocarpal and distal radio-ulnar joints. Intra-articular malunion may lead to posttraumatic radiocarpal osteoarthritis. ${ }^{2}$ The functional impact of this has not been clearly defined.

It is difficult to draw any conclusions from the literature concerning fractures of the distal radius because of the wide range of patients, interventions, methodology and measures of outcome. $^{3-5}$ There is some evidence to support the use of external fixation or percutaneous pinning, but it is "unclear whether surgical intervention for most fracture types will produce consistently better long-term outcomes". 3 We have observed the increasing use of internal fixation, both within our own institution and in the literature, because of the improved reduction which can be achieved, but it is uncertain whether this results in a better functional outcome and a reduced risk of post-traumatic osteoarthritis. ${ }^{6}$ Associated injury to the intercarpal ligaments may explain the failure to identify improved functional outcome from better radiological reduction. ${ }^{7}$

Young patients with high-energy fractures are often considered as a sub-group in which malunion should be prevented by using operative fixation. They are distinguished from patients with low-energy fractures not involving the wrist, the classical Colles' fracture, and it is generally agreed that younger patients with greater physical demands are at the most risk of disability from a poor result after such a fracture. In addition, their long remaining working life may place them at a greater risk of developing post-traumatic osteoarthritis.

We have examined the prevalence of malunion and post-traumatic arthritis and investigated their relation to symptoms in a group of adults who had sustained a fracture of the distal radius at least 33 years previously, when aged less than 40 years. 
Table I. Details of the intra- and extra-articular groups

\begin{tabular}{|c|c|c|c|}
\hline & Overall $(n=106)$ & Intra-articular $(n=40)$ & Extra-articular $(n=66)$ \\
\hline Mean age at injury in yrs (range) & $25(16$ to 40$)$ & 27 (16 to 40$)$ & 24 (16 to 40$)$ \\
\hline Mean age at follow-up in yrs (range) & 64 (51 to 80$)$ & 65 (53 to 79$)$ & $63(51$ to 80$)$ \\
\hline $\begin{array}{l}\text { Mean length of follow-up in yrs } \\
\text { (range) }\end{array}$ & 38 (33 to 42 ) & 38 (34 to 42 ) & 39 (33 to 42 ) \\
\hline \multicolumn{4}{|l|}{ Gender } \\
\hline$M: F$ & $74: 32$ & 29:11 & $45: 21$ \\
\hline \multicolumn{4}{|l|}{ Dominant hand fractured } \\
\hline $\mathrm{Y}: \mathrm{N}$ & $49: 57$ & $17: 23$ & $32: 34$ \\
\hline \multicolumn{4}{|l|}{ Occupation } \\
\hline Heavy manual & 54 & 21 & 33 \\
\hline Clerical & 33 & 13 & 20 \\
\hline $\begin{array}{l}\text { Dextrous (requires fine } \\
\text { motor skills) }\end{array}$ & 19 & 6 & 13 \\
\hline \multicolumn{4}{|l|}{ Mechanism of injury } \\
\hline Fall & 71 & 27 & 44 \\
\hline Road-traffic accident & 21 & 7 & 14 \\
\hline Crush & 4 & 2 & 2 \\
\hline Direct blow & 10 & 4 & 6 \\
\hline \multicolumn{4}{|l|}{ Treatment } \\
\hline Colles' plaster & 64 & 19 & 45 \\
\hline Manipulation + Colles' plaster & 10 & 5 & 5 \\
\hline $\mathrm{GA}^{*}+$ Colles' plaster & 31 & 15 & 16 \\
\hline Internal fixation & 1 & 1 & 0 \\
\hline
\end{tabular}

\section{Patients and Methods}

This retrospective observational study was carried out in the hand surgery clinic of a university teaching hospital. The study received ethical approval and all the patients provided informed consent. The contralateral uninjured wrist was used as a control.

Ledgers maintained in the plaster room containing the details of all the patients who had a plaster cast applied to their arm between 1960 and 1968 at our institution, which was the main local provider of emergency services at this time, were obtained from the Archive Department of the University Library. The details contained the name, address at the time of application of the cast, age but not date of birth, and gender. These data were used to attempt to locate the patients who were under the age of 40 years at the time of their injury using the hospital computer database, the Electoral Register and Local Health Authority records.

We identified 801 patients as having received a belowelbow plaster cast for an unspecified reason during this period of nine years. Of these, 235 were traced, of whom 49 had died, 15 had not sustained a fracture of the distal radius and five were considered to be unfit by their general practitioner to participate in the study. A total of 47 patients did not wish to take part. We reviewed the remaining 119 patients, and a further 13 were excluded because they had sustained a subsequent fracture of the contralateral wrist. This left 106 patients of the 153 eligible, a follow-up rate of $69 \%$, but only $13 \%$ of the original 801 patients.

These were 74 males and 32 females, whose mean age at injury was 25 years ( 16 to 40 ) and at follow-up 64 years (51 to 80 ). The mean length of follow-up was 38 years (33 to $42)$. A total of 49 patients $(46 \%)$ had injured their dominant hand. Other characteristics of the patients are shown in Table I. Radiographs from one of the most malunited fractures are shown in Figure 1.

The primary outcome measure was objective hand function as assessed by the grip strength and range of movement (ROM). The former was measured in both hands, taking the best of three attempts using a Jamar Dynamometer (J. A. Preston, Jackson, Michigan) and the ROM by a goniometer using standard techniques and positions.

A composite value for the ROM for each wrist was calculated by the addition of the ranges of flexion, extension, radial and ulnar deviation and pronation and supination.

Secondary outcome measures included pain in the wrist which was assessed using a visual analogue scale, the hand health profile section of the Patient Evaluation Measure, the disabilities of the arm, shoulder and hand (DASH) questionnaire, ${ }^{8-10}$ and the radiological evidence of osteoarthritis. The DASH and Patient Evaluation Measure were both validated for assessing hand function, unlike the assessments of function used in many previous investigations of the distal radius. ${ }^{11-13}$ A comparative Patient Evaluation 


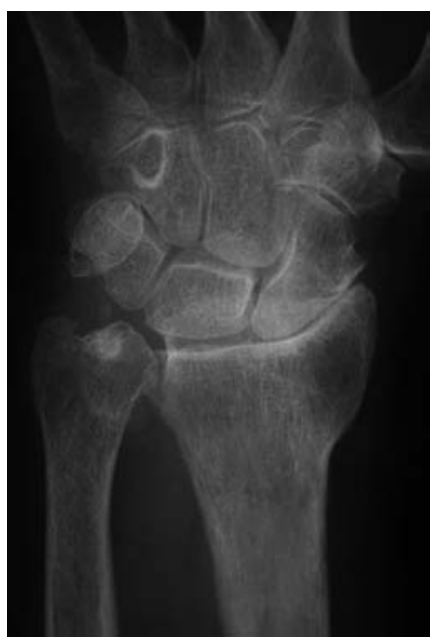

Fig. 1a

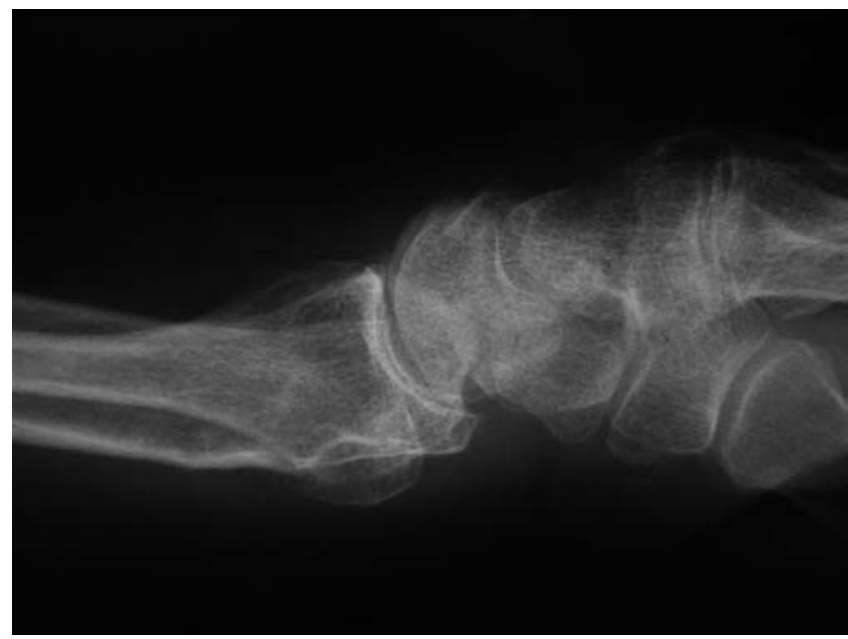

Fig. 1b

Radiographs showing a) posteroanterior and b) lateral views of a malunited fracture. This woman sustained her injury at the age of 36 years and was reviewed 38 years later. She reported only occasional symptoms despite obvious malunion and joint degeneration.

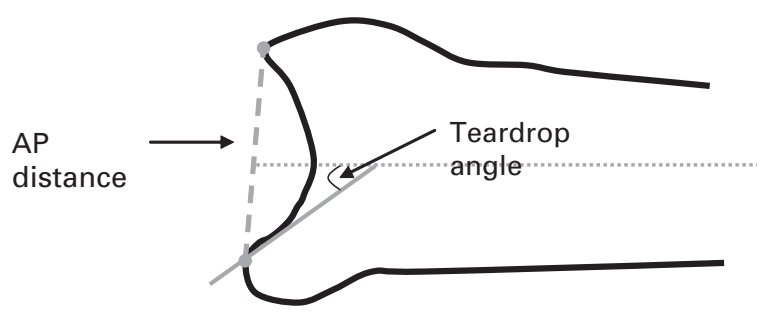

Fig. 2

Diagram showing the anteroposterior (AP) distance and teardrop angle. ${ }^{16}$

Measure was also calculated by obtaining scores for the uninjured and injured arms separately, and subtracting the uninjured score from that of the injured one. This attempted to eliminate any symptoms present from other problems such as trapeziometacarpal arthritis, which is prevalent in this group of patients and a confounding factor not usually considered when reviewing outcome. ${ }^{14}$

The characteristics of the fractures were documented using standard radiographs of both the injured and uninjured wrists. ${ }^{2,15,16}$ The criteria described by Jupiter and Fernandez ${ }^{1}$ were used to define the presence of malunion: $<20^{\circ}$ of radial angulation, dorsal angulation beyond neutral and shortening of $2 \mathrm{~mm}$ or more in comparison with the contralateral wrist. ${ }^{17}$ The teardrop angle and anteroposterior (AP) distance were also assessed (Fig. 2). ${ }^{16}$ Both have only recently been recognised, and some authors consider them to be of vital importance. ${ }^{16}$ The degree of narrowing of the radiocarpal joint space, the formation of osteophytes, sclerosis and the formation of cysts were also individually recorded, as well as the grade of any post-
Table II. Classification of post-traumatic osteoarthritis according to Knirk and Jupiter ${ }^{2}$

\begin{tabular}{ll}
\hline Grade & Radiological findings \\
\hline 0 & Normal \\
1 & Slight narrowing of the joint space \\
2 & Marked narrowing, formation of osteophytes \\
3 & $\begin{array}{l}\text { Bone-on-bone narrowing, formation of cysts } \\
\text { and osteophytes }\end{array}$ \\
\hline
\end{tabular}

traumatic osteoarthritis according to Knirk and Jupiter ${ }^{2}$ (Table II).

Since the original radiographs were not available, classification into intra- and extra-articular fractures was made on those obtained at the latest follow-up. The characteristics used to identify an intra-articular fracture were any persistent articular step or gap, the obvious presence of a healed fracture line extending into the joint and an increase of $4 \mathrm{~mm}$ in the AP distance of the injured compared with the uninjured wrist as seen on the lateral view. We felt that increases in the AP distance indicated a previous comminuted intra-articular fracture with dorsal and palmar fragments which had united with a gap between them. The accuracy of using the AP distance to identify intra-articular fractures was confirmed using 92 sets of radiographs from a contemporary group of patients in whom radiographs were all available at the time of injury, after reduction of the fracture and at union. A threshold of an increase of $4 \mathrm{~mm}$ in the AP distance in the fractured wrist compared with the uninjured wrist at union identified 17 of 55 displaced intra- 
Table III. Radiological details of both groups

\begin{tabular}{|c|c|c|c|c|c|c|}
\hline & \multicolumn{2}{|c|}{ Overall $(n=106)$} & \multicolumn{2}{|c|}{ Intra-articular $(n=40)$} & \multicolumn{2}{|c|}{ Extra-articular $(n=66)$} \\
\hline & $\begin{array}{l}\text { Fractured } \\
\text { wrist }\end{array}$ & $\begin{array}{l}\text { Contralateral } \\
\text { wrist }\end{array}$ & $\begin{array}{l}\text { Fractured } \\
\text { wrist }\end{array}$ & $\begin{array}{l}\text { Contralateral } \\
\text { wrist }\end{array}$ & $\begin{array}{l}\text { Fractured } \\
\text { wrist }\end{array}$ & $\begin{array}{l}\text { Contralateral } \\
\text { wrist }\end{array}$ \\
\hline Mean $\left(95 \% \mathrm{Cl}^{*}\right)$ palmar tilt $\left(^{\circ}\right)$ & $2(0$ to 4$)$ & $11(10$ to 12$)$ & $-1(-5$ to +3$)$ & 11 (10 to 13$)$ & $4(2$ to 7$)$ & $11(10$ to 12$)$ \\
\hline Mean $(95 \% \mathrm{Cl})$ radial angulation $\left({ }^{\circ}\right)$ & $23(22$ to 24$)$ & 26 (26 to 27$)$ & 21 (18 to 23 ) & 26 (25 to 27$)$ & $24(23$ to 26$)$ & 26 (25 to 27$)$ \\
\hline Mean $(95 \% \mathrm{Cl})$ radial length $(\mathrm{mm})$ & 12 (11 to 13$)$ & $14(14$ to 14$)$ & 11 (10 to 12$)$ & $14(13$ to 14$)$ & $13(12$ to 14$)$ & 14 (13 to 15$)$ \\
\hline Mean $(95 \% \mathrm{Cl})$ teardrop angle $\left({ }^{\circ}\right)$ & $60(57$ to 62$)$ & $68(67$ to 70$)$ & $56(52$ to 60$)$ & $68(66$ to 70$)$ & $62(59$ to 64$)$ & $69(67$ to 70$)$ \\
\hline Mean $(95 \% \mathrm{Cl}) \mathrm{AP}^{\dagger}$ distance $(\mathrm{mm})$ & $20(19$ to 21$)$ & 19 (18 to 19$)$ & 22 (21 to 23 ) & $19(19$ to 20$)$ & 19 (18 to 19$)$ & 19 (18 to 19$)$ \\
\hline
\end{tabular}

* $95 \% \mathrm{Cl}, 95 \%$ confidence interval

† AP, anteroposterior

\begin{tabular}{|c|c|c|}
\hline Dorsal angulation $\left({ }^{\circ}\right)$ & 11 & (8 to 14 ) dorsal \\
\hline Dorsal angulation vs uninjured wrist $\left({ }^{\circ}\right)$ & 22 & (18 to 25$)$ \\
\hline Reduction in radial angle $\left({ }^{\circ}\right)$ & 8 & $(6$ to 10$)$ \\
\hline Shortening (mm) & 3.5 & (2.1 to 4.8$)$ \\
\hline Increase in anteroposterior distance $(\mathrm{mm})$ & 2 & (1 to 3 ) \\
\hline Range of movement vs uninjured wrist (\%) & 96 & (94 to 98$)$ \\
\hline Flexion vs that of uninjured wrist (\%) & 80 & ( 75 to 86 ) \\
\hline Grip strength vs that of uninjured wrist (\%) & 87 & (81 to 93 ) \\
\hline Patient Evaluation Measure increase (\%) & 5 & $(2$ to 8$)$ \\
\hline Mean DASH ${ }^{*}$ score & 5 & (2 to 8$)$ \\
\hline \multicolumn{3}{|l|}{ Grade of arthritis $(n=35)$} \\
\hline 0 & 14 & \\
\hline 1 & 11 & \\
\hline 2 & 8 & \\
\hline 3 & 2 & \\
\hline
\end{tabular}

articular injuries and three of 25 undisplaced articular injuries, with no misclassification of extra-articular injuries. Although such a threshold is insensitive (sensitivity $33 \%$ ), it is $100 \%$ specific for identifying intra-articular injuries. Injuries classified as intra-articular in our study therefore probably represented severe intra-articular injuries with palmar and dorsal fragments which were not reduced, leading to residual articular incongruity. Those considered as extra-articular contained some intra-articular injuries, but with less displacement.

The physical examination was performed by the principal author (DPF) without reference to the side of injury or access to radiographs. The accuracy of the findings on examination and the radiological assessments were independently verified by repeat examination by a second observer in 40 cases.

Statistical analysis. The articular injuries were considered in two groups, those with articular displacement (intraarticular fractures) and those with extra-articular malunion with or without undisplaced articular extensions (extra-articular fractures). In addition to the use of the $t$-test, chi-squared test, Fisher's exact test and calculation of the Pearson correlation coefficient for univariate analysis, two separate multivariate analyses were performed. These had the advantage of considering the characteristics of the fractures independently as individual explanatory variables, such that all 106 patients contributed to each analysis, and therefore avoided decreasing patient numbers in sub-group analyses. For the objective measures of grip strength and ROM, an analysis of covariance (ANCOVA) was used to quantify their relationship to radiological factors including dorsal angulation, radial deviation, radial shortening, the teardrop angle and the AP distance. Log transformation to satisfy requirements of normality was performed for data which were skewed. For the subjective measures an ordinal logistic regression model was used to analyse the data, which was scored on a scale from 1 to 7 . For each of the ten questions of the Patient Evaluation Measure score a separate analysis was performed, as well as for the overall total score and for the DASH score, adjusting for explanatory variables such as age, gender and hand dominance. Both sets of analyses were performed using the SAS package version 9.2 (SAS Institute Inc., Cary, North Carolina).

\section{Results}

Of the 106 patients, five had changed occupation, but in none was this because of the fracture, and none reported any restriction to their work activities as a result of the injury. No salvage procedures had been performed on any of the patients. One had undergone internal fixation with two inter-fragmentary screws for treatment of his fracture. Surgeons practising in the hospital at the time have confirmed that manipulation and application of plaster were the standard treatment and that internal fixation was seldom performed.

Radiological findings. According to the definition of Jupiter and Fernandez, ${ }^{1} 69$ of the fractures $(65 \%)$ had united with malunion, including $19(18 \%)$ which were malunited in all three parameters. In the extra-articular group only the AP distance, a measure of disruption of the articular surface, was not significantly different in the fractured compared with the uninjured wrists (paired $t$-test, $\mathrm{p}=0.171$, Table III). The values for the AP distance in the uninjured wrist were similar to already published figures (mean $18.8 \mathrm{~mm}$; 
Table V. Grading of osteoarthritis for all patients and those with intra-articular fractures, by number and percentage

\begin{tabular}{lllllll}
\hline & \multicolumn{2}{l}{ All patients $\mathbf{( n = 1 0 6 )}$} & & \multicolumn{2}{l}{ Intra-articular fractures $\mathbf{( n = 4 0 )}$} \\
\cline { 2 - 3 } Grade & Fractured wrist & Uninjured wrist & & Fractured wrist & Uninjured wrist \\
\hline 0 & $50(47)$ & $78(74)$ & $13(32.5)$ & $30(75)$ \\
1 & $31(29)$ & $20(19)$ & $13(32.5)$ & $8(20)$ \\
2 & $21(20)$ & $8(7)$ & $12(30)$ & $2(5)$ \\
3 & $4(4)$ & $0(0)$ & $2(5)$ & 0 & $(0)$ \\
\hline
\end{tabular}

Table VI. Comparison of grading of osteoarthritis between fractured and contralateral wrists, by number and percentage

\begin{tabular}{llcc}
\hline Fractured $\boldsymbol{v s}$ uninjured wrist & Overall $(\mathbf{n}=\mathbf{1 0 6})$ & Intra-articular $\mathbf{( n = 4 0 )}$ & Extra-articular $(\mathbf{n}=\mathbf{6 6})$ \\
\hline 2 grades worse & $12(11)$ & $8(20)$ & $4(6)$ \\
1 grade worse & $34(32)$ & $16(40)$ & $18(27)$ \\
Same grade & $53(50)$ & $15(37.5)$ & $38(58)$ \\
1 grade better & $5(5)$ & $1(2.5)$ & $4(6)$ \\
2 grades better & $2(2)$ & $0(0)$ & $2(3)$ \\
\hline
\end{tabular}

$95 \%$ confidence interval (CI) 17 to 21$).{ }^{16}$ In Table III the amount of dorsal angulation observed appears to be small, (mean palmar tilt $2^{\circ}$ (95\% CI 0 to 4 ) but this is because 26 $(24.5 \%)$ of the 106 fractures were of the Smith and not the Colles' type, and had united with palmar angulation of more than $10^{\circ}$. For the 35 fractures $(33 \%)$ which united with dorsal angulation beyond neutral the range of malunion was from $2^{\circ}$ to $38^{\circ}$, with a mean of $11^{\circ}\left(22^{\circ}\right.$ dorsal angulation relative to the uninjured wrist, Table IV). Post-traumatic osteoarthritis. There was a significantly greater degree of radiological degeneration in the fractured wrist compared with the uninjured side (chi-squared test $28.1, \mathrm{p}=0.0001)$. Overall, 53 of the 106 fractures $(50 \%)$ were assigned the same osteoarthritis grading in both the fractured and uninjured wrists. In $46(43.4 \%)$ a higher grade was assigned on the fractured side and in seven $(6.6 \%)$ a lower one. Intra-articular fractures had a greater proportion of arthritis than those which did not involve the joint (Tables V and VI). However, 26 of 40 (65\%) intra-articular fractures were considered to have grade 0 or grade 1 arthritis, with mild narrowing of the joint space at most.

After adjusting for other variables, ordinal logistic regression analysis showed a significant relationship between narrowing of the joint space and dorsal angulation, radial shortening and intra-articular injury (odds ratio (OR) $(95 \%$ CI) 1.07 (1.03 to 1.1$), 1.21$ (1.02 to 1.45$)$ and 3.23 (1.43 to 7.14 ), respectively). Radial angulation was not a significant determinant of narrowing of the joint space. The OR suggested that dorsal angulation of $10^{\circ}$, i.e. $20^{\circ}$ of angular deformity from the normal palmar tilt, resulted in the fractured wrist being 1.2 times more likely to have worse narrowing of the joint space than that without loss of the normal palmar tilt. Radial shortening of $2 \mathrm{~mm}$ resulted in the fractured wrist being 2.4 times more likely to have worse narrowing than that with no shortening, and an intra-articular injury was 3.2 times more likely to have more narrowing than an extra-articular injury.

Formation of osteophytes was not significantly related to dorsal angulation, radial deviation, radial shortening, positive ulnar variance or the presence of an intra-articular injury or carpal malalignment. An increase in the formation of osteophytes was observed in the fractured wrist with increasing age at injury (OR 1.06 (95\% CI 1.01 to 1.11$)$ ), such that for every decade increase in age patients were ten times more likely to have worsening osteophyte formation in the injured, but not the uninjured wrist. The presence of osteophytes in the uninjured wrist made their appearance in the fractured wrist six times more likely (OR 6.29 (95\% CI 3.34 to 11.76$)$ ).

The only significant predictor of sclerosis at the radiocarpal joint following fracture was an intra-articular injury (OR 5.88 (95\% CI 2.44 to 14.29 )). Intra-articular fractures were 5.9 times more likely to have sclerosis than extraarticular injuries. Formation of cysts was only significantly related to the presence of cysts in the uninjured side (OR 18.9 (95\% CI 3.97 to 90.9)), almost 19 times more likely. Outcome measures. Multivariate analysis suggested that the range of movement in the fractured wrist, when expressed as a proportion of the uninjured side, was reduced to $92 \%\left(323^{\circ}\right.$ of $\left.351^{\circ}\right)$ when there was a step in the joint surface, compared with $98 \%\left(344^{\circ}\right.$ of $\left.351^{\circ}\right)$ when no step was present (ANCOVA, $\mathrm{p}=0.004$ ). This deficit mainly arose from a mean loss of $10^{\circ}$ flexion in the intra-articular fractures and was explained by joint degeneration (Table VII). It was not possible to identify thresholds for extraarticular malunion beyond which the clinical or functional outcome was significantly reduced. Rotation of the forearm showed very little reduction on the fractured side with a mean of $5^{\circ}$. Multivariate analysis of grip strength as a percentage of that of the uninjured wrist suggested that dorsal angular malunion caused grip strength to fall to $89 \%$ of 
Table VII. The effects of arthritis on flexion

\begin{tabular}{lc}
\hline $\begin{array}{l}\text { Grade of fractured compared with } \\
\text { that of uninjured wrist }\end{array}$ & $\begin{array}{l}\text { Flexion in the fractured wrist as a } \\
\text { percentage of that of the uninjured wrist }\end{array}$ \\
\hline 2 grades worse & 63 \\
1 grade worse & 77 \\
Same grade & 98 \\
1 grade better & 122 \\
2 grades better & 120 \\
\hline
\end{tabular}

Table VIII. Outcome measures (mean percentage, 95\% confidence interval) 38 years after a distal radial fracture comparing the injured with the uninjured wrist

\begin{tabular}{lllll}
\hline & $\begin{array}{l}\text { Intra-articular } \\
\text { (n= 40) }\end{array}$ & p-value & $\begin{array}{l}\text { Extra-articular } \\
\text { (n= 66) }\end{array}$ & p-value \\
\hline Range of movement (\%) & $95(92$ to 98) & $0.003^{*}$ & $98(97$ to 99) & $0.002^{*}$ \\
Grip strength (\%) & $94(86$ to 102) & $0.037^{*}$ & $96(91$ to 101$)$ & 0.069 \\
Pain severity (\%) & $4(-2$ to +10) & 0.212 & $1(-1$ to +3) & 0.199 \\
Patient Evaluation Measure Increase (\%) & $9(5$ to 15) & $0.001^{*}$ & $5(2$ to 8$)$ & $0.001^{*}$ \\
\hline * significance (t-test) & & & &
\end{tabular}

that of the uninjured side, compared with $99 \%$ of that of the uninjured side when no dorsal malunion was present (ANCOVA, $\mathrm{p}<0.001$ ), but again no clear threshold could be identified.

Pain. This was not related to the grading of Knirk and Jupiter $^{2}$ or any other marker of osteoarthritis or malunion on ordinal logistic regression analysis (general linear model (GLM), p > 0.21). Overall, $81 \%$ (86 of 106) of fractured wrists and $91 \%$ (96 of 106) of uninjured wrists were reported to be painless at the time of assessment (chisquared test $4.83, \mathrm{p}=0.03$ ), but the intensity of pain was not significantly greater in the fractured wrist compared with the uninjured side, or in the intra- or extra-articular subgroups (ordinal logistic regression GLM, p > 0.124).

Function. As assessed by the Patient Evaluation Measure, this was worse in the injured than in the uninjured wrists (Table VIII). The difference in the level of function between the two sides was small with a deficit of $5 \%$ for extraarticular fractures and $9 \%$ for those involving the joint $(t$ test, $\mathrm{p}<0.01$ ). While these differences were statistically significant, they may not have been so clinically as $10 \%$ is the lowest threshold that has been used for clinical significance in the Patient Evaluation Measure score. ${ }^{18}$ The effect size, the difference in means between the fractured and uninjured wrists divided by their pooled SD, for the intraarticular group was 0.60 and for the extra-articular group 0.43 whereas it has been suggested that it needs to be greater than 0.8 to achieve clinical significance. ${ }^{19}$ Measures of extra-articular malunion were not significantly related to function (ordinal logistic regression GLM, p > 0.05).

The mean DASH score was significantly different between the intra-articular (mean 13 (95\% CI 6 to 20)) and extra-articular (mean $9(95 \%$ CI 4 to 14$))$ injuries (t-test, $\mathrm{p}=0.03)$. As with the results of the Patient Evaluation Measure assessment, this was statistically significant, but may not have been clinically relevant with effect sizes of 0.48 and 0.62 , respectively, and the low scores indicated minimal disability in both groups. The mean DASH score for a comparative 'control' population in North America was 10 , with an SD of 15 points, ${ }^{20}$ which indicated that the level of function in the fracture group was very similar to normal levels.

Wrists with grade 3 post-traumatic osteoarthritis were almost ten times more likely to have worse function than grade 0 wrists, using the Patient Evaluation Measure score (OR 9.6 (95\% CI 2.5 to 36.3), ordinal logistic regression GLM, $\mathrm{p}=0.001)$. The mean Patient Evaluation Measure score for grade 0 wrists was $8 \%$ and for grade 3 wrists $18 \%$ indicating that although function was worse, the difference was small and the effect size was 0.60 , below the level of 0.8 set for clinical significance. ${ }^{19}$ The only significant predictor of loss of function in the Patient Evaluation Measure score observed in the fractured wrist on ordinal logistic regression analysis (GLM) was a change in the teardrop angle in which for every reduction of $1^{\circ}$, the Patient Evaluation Measure score was $1 \%$ lower $(\mathrm{p}=0.03)$. The lowest teardrop angle observed was $18^{\circ}$, a substantial reduction from the normal $70^{\circ}$.

\section{Discussion}

This long-term outcome study of fractures of the distal radius in young adults has shown an increase of $43 \%$ in the prevalence of radiological changes of osteoarthritis in the fractured wrists in a population in which the prevalence of malunion ( $>20^{\circ}$ dorsal angulation, $\geq 2 \mathrm{~mm}$ shortening) was $65 \%$ and has quantified the risk factors for this and the clinical outcome. The clinical assessors were blind to any history of the previous injury and there was no access to any radiographs, although the cosmetic deformity often indicated extra-articular malunion. Standard objective 
methods and validated self-reported questionnaires were also used. The radiographs were all assessed subsequently without reference to the clinical results in order to reduce any observer bias. The results from assessment of the radiological parameters in the uninjured wrists were similar to those published previously and assessment by a second observer in a selection of the cases suggested that our methods were accurate.

Function as assessed by the Patient Evaluation Measure was significantly worse in the injured wrists, and more so in intra-articular injuries, but this was of uncertain clinical relevance. The recorded DASH scores were very similar to the means in a comparative normal population. ${ }^{20}$

We have not been able to identify any thresholds of malunion beyond which function was clearly worse as measured by the Patient Evaluation Measure and DASH scores. Dorsal angulation and shortening were both associated with worse function, with each $1 \mathrm{~mm}$ of shortening having a greater effect on function than each $10^{\circ}$ of dorsal angular malunion. Intra-articular malunion was a greater predictor of reduced function scores than either of these extraarticular measurements.

Intra-articular fractures. The evidence from our study may appear to contradict that of Knirk and Jupiter ${ }^{2}$ which implied that clinically relevant post-traumatic osteoarthritis complicates many of these injuries, especially those which unite with incongruity of the radiocarpal joint. They reviewed 43 fractures in 40 patients and noted radiological evidence of post-traumatic osteoarthritis in $91 \%$ of the 24 wrists with residual incongruity of the radiocarpal joint when reviewed at a mean of seven years. However, only one of their 40 patients with intra-articular fractures stated that their fracture had stopped them from working and 11 had no pain in the wrist. A further 25 had slight pain on exertion and only four had pain during their normal activities. The remaining two experienced pain at rest, although both of their intra-articular fractures had healed with no incongruity of the joint. One had no evidence of post-traumatic arthritis and the other had only mild narrowing of the joint space. Although $24(56 \%)$ of the 43 intra-articular fractures showed radiological evidence of post-traumatic osteoarthritis, in $20(46.5 \%)$ this was only grade 1 . The remaining four $(9.3 \%)$ had marked narrowing of the joint space with osteophytes, but only one $(2.3 \%)$ had severe (grade 3) changes.

Of our intra-articular fractures 26 of $40(65 \%)$ had grade 0 or grade 1 arthritis at 38 years (Table V), rather less than the $91 \%$ (39 of 43 ) seen by Knirk and Jupiter ${ }^{2}$ at seven years. After 38 years we observed a prevalence of grade 2 arthritis of $30 \%$ (12 of 40), and of grade 3 changes of $5 \%$ ( 2 of 40$)$. The comparable figures from Knirk and Jupiter $^{2}$ were $7 \%$ and $2 \%$ respectively suggesting that onethird of the wrists with grade 1 changes at seven years progressed with time to grade 2 or grade 3 without the development of severe symptoms, while the other two-thirds did not change radiologically or clinically. We consider that much of the grade 1 change observed represented a nonprogressive injury to the cartilage which occurred at the time of injury and that most wrists with radiological osteoarthritis did not progress to produce symptoms.

Fractures involving the radiocarpal joint were 3.2 times more likely to have radiological evidence of arthritis, a lower figure than that noted by Kreder et $\mathrm{al}^{21}$ in a randomised controlled trial of plate fixation. They found a 9.9-fold increase in the risk of radiological osteoarthritis when there was persistent articular incongruity. However, they demonstrated no functional differences at follow-up of one year.

Stiffness was more marked in displaced articular fractures (ROM $95 \%$ of the uninjured side) than in the extraarticular group (ROM 98\%, ANCOVA, $\mathrm{p}=0.003$ ). Most of this difference was accounted for by a loss of flexion. The difference in symptoms between the intra- and extra-articular groups as assessed by comparison of the Patient Evaluation Measure scores of the injured and contralateral wrists, was small, and below the $10 \%$ difference considered as the limit of clinical significance, with a correspondingly small effect size $(\leq 0.60)$.

Extra-articular malunion. Increasing dorsal angulation and radial shortening were significantly associated with radiological degeneration in our series, a finding common to some previous studies, ${ }^{2,22-28}$ but not to others which considered radial angulation to be important. ${ }^{29-34}$ It is possible that these parameters measured similar deformities since a change in the radial angle could affect the radial length. One report has suggested that neither dorsal angulation nor radial length is important, ${ }^{35}$ but our multivariate analysis confirmed the association between dorsal angulation, shortening and narrowing of the joint space. It may be that dorsal angulation is a marker for dorsal comminution of the initial fracture. ${ }^{36}$

Our analysis also showed a significant, but small, effect of dorsal angulation on flexion with each increase of $10^{\circ}$ in the dorsal angulation resulting in a loss of flexion of $3^{\circ}$ and an increase of $2^{\circ}$ in extension. Catalano et $\mathrm{al}^{37}$ also found that flexion was the only outcome variable which correlated with bony displacement. Kopylov et $\mathrm{a}^{28}$ noted a loss of flexion of $6^{\circ}$ overall in 76 patients reviewed at 30 years. Smaill ${ }^{38}$ reported a loss of flexion of $8^{\circ}$ in 41 patients seen at five to six years after a distal fracture of the radius.

No measure of extra-articular malunion was significantly associated with either the Patient Evaluated Measure or DASH scores. Although subjective questionnaires are presently a popular measure of outcome, the use of subjective measures alone has been questioned. ${ }^{39,40}$ We considered that the measurements of hand strength and range of movement combined with subjective responses would demonstrate an effect of malunion if one were present.

Pain. The intensity of pain was not significantly different between the fractured and uninjured wrists. Pain from the uninjured side has not been assessed in most outcome studies, and it is usually assumed that the contralateral wrist is not painful. However, as patients become older they will 
develop constitutional degenerative changes independent of the distal radial fracture. For example, the radiological changes at the base of the thumb in patients with a distal radial fracture increase steadily from the age of 41 years and reach a prevalence of $91 \%$ in those over 80 years. ${ }^{14}$ This and other similar levels of deterioration must have an effect on the symptoms reported in any follow-up study, but are not normally assessed or controlled for. Conditions such as trapeziometacarpal osteoarthritis, although typically bilateral, may only be symptomatic in one hand indicating that the contralateral hand is not a perfect control. However, when groups of subjects are compared, the distribution of such comorbidities will even out and are not influenced by the fracture of the distal radius.

Limitations. Only $13 \%$ of the original cohort of 801 subjects, some of whom may not have had fractures of the distal radius, were traced, but $69 \%$ of the eligible fractures which were traced were studied. Low rates of follow-up are an inevitable problem in retrospective long-term studies and our ability to trace patients was considerably hampered by knowledge only of the age at injury, rather than the date of birth, of the patients. However, we feel that this was unlikely to represent a significant bias. If there had been a significant incidence of symptomatic osteoarthritis we would have expected that the patients would have returned to our hospital for treatment since it is the only provider of wrist surgery in the city.

Recall bias would have been a significant problem if we had relied on patients recalling information about their injury and treatment. We were clear to relate only the final anatomical appearances to the symptoms and objective findings at the time of follow-up. Therefore no further recall was required.

We conclude that the long-term clinical outcome of intraarticular fractures may not be as poor as suggested by the study of Knirk and Jupiter, ${ }^{2}$ although they also found that most subjects experienced either no pain or mild pain after use. Our results support the belief that slight narrowing of the joint space is often a benign condition which does not progress and result in more severe, clinically relevant, posttraumatic osteoarthritis. ${ }^{37,41}$

We consider that if anatomical intra- or extra-articular reduction cannot be achieved with simple treatment options such as closed reduction and Kirschner wiring or the application of an external fixator, then the long-term clinical outcome will probably still be satisfactory. It may not be necessary to resort to complex internal fixation which may itself produce complications and may not be cost-effective.

\section{Supplementary Material}

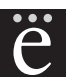
A further opinion by Mr. D Warwick is available with the electronic version of this article on our website at www.jbjs.org.uk

We thank Mr S. Milner, Consultant Orthopaedic Surgeon, who acted as the second observer for the patient and radiological reviews.

No benefits in any form have been received or will be received from a commercial party related directly or indirectly to the subject of this article.

\section{References}

1. Jupiter JB, Fernandez DL. Complications following distal radial fractures. Instr Course Lect 2002;51:203-19.

2. Knirk JL, Jupiter JB. Intra-articular fractures of the distal end of the radius in young adults. J Bone Joint Surg [Am] 1986;68-A:647-59.

3. Handoll HH, Madhok R. Surgical interventions for treating distal radial fractures in adults. Cochrane Database Syst Rev 2003;3:CD003209.

4. Handoll HH, Madhok R. Conservative interventions for treating distal radial fractures in adults. Cochrane Database Syst Rev 2003;2:CD000314.

5. Kreder HJ. Review: evidence on surgical interventions for distal radial fractures is inconclusive. ACP J Club 2002;136:112.

6. Wright TW, Horodyski M, Smith DW. Functional outcome of unstable distal radius fractues: ORIF with a volar fixed-angle tine plate versus external fixation. J Hand Surg 2005;30:289-99.

7. Forward DP, Lindau TR, Melsom DS. Intercarpal ligament injuries associated with fractures of the distal part of the radius. J Bone Joint Surg [Am] 2007;89-A:2334-40.

8. Hudak PL, Amadio PC, Bombardier C. Development of an upper extremity outcome measure: the DASH (disabilities of the arm, shoulder and hand) [corrected]. Am $J$ Ind Med 1996;29:602-8.

9. Macey AC, Burke FD, Abbott K, et al. Outcomes of hand surgery. J Hand Surg [Br] 1995;20:841-55.

10. Gummesson C, Atroshi I, Ekdahl C. The disabilties of the arm, shoulder and hand (DASH) outcome questionnaire: logitudinal construct validity and measuring selfrated health change after surgery. BMC Musculoskelet Disord 2003;16:4-11.

11. Sharma R, Dias JJ. Validity and reliability of three generic outcome measures for hand disorders. J Hand Surg [Br] 2000;250:593-600.

12. Dias JJ, Bhowal B, Wildin CJ, Thompson JR. Assessing the outcome of disor ders of the hand: is the patient evaluation measure reliable, valid, responsive and without bias? J Bone Joint Surg [Br] 2001;83-B:235-40.

13. Forward DP, Sithole JS, Davis TR. The internal consistency and validity of the Patient Evaluation Measure for outcomes assessment in distal radius fractures. $J$ Hand Surg (Eur Vol) 2007;32:262-7.

14. Sodha S, Ring D, Zurakowski D, Jupiter JB. Prevalence of osteoarthritis of the trapeziometacarpal joint. J Bone Joint Surg [Am] 2005;87-A:2614-18.

15. van der Linden W, Ericson R. Colles' fracture: how should its displacement be measured and how should it be immobilized? J Bone Joint Surg [Am]1981;63-A:1285-

16. Medoff RJ. Essential radiographic evaluation for distal radius fractures. Hand Clin 2005;21:279-88.

17. Fourrier P, Bardy A, Roche G, Cisterne JP, Chambon A. Approach to a definition of mal-union callus after Pourteau-Colles fractures. Int Orthop 1981;4:299-305 (in French).

18. Dias JJ, Wildin CJ, Bhowal B, Thompson JR. Should acute scaphoid fractures be fixed?: a randomized controlled trial. J Bone Joint Surg [Am] 2005;87-A:2160-8.

19. Rosnow RL. Effect sizes for experimenting psychologists. Can J Exp Psychol 2003;57:221-37.

20. Hunsaker FG, Cioffi DA, Amadio PC, Wright JG, Caughlin B. The American academy of orthopaedic surgeons outcomes instruments: normative values from the general population. J Bone Joint Surg [Am] 2002;84-A:208-15.

21. Kreder HJ, Hanel DP, Agel J, et al. Indirect reduction and percutaneous fixation versus open reduction and internal fixation for displaced intra-articular fractures of the distal radius: a randomised, controlled trial. J Bone Joint Surg [Br]2005;87-B:82936.

22. Gartland JJ Jr, Werley CW. Evaluation of healed Colles' fractures. J Bone Joint Surg [Am] 1951;33-A:895-907.

23. Cooney WP 3rd, Dobyns JH, Linscheid RL. Complications of Colles' fractures. J Bone Joint Surg [Am] 1980;62-A:613-19.

24. Bradway JK, Amadio PC, Cooney WP. Open reduction and internal fixation of displaced, comminuted intra-articular fractures of the distal end of the radius. J Bone Joint Surg [Am] 1989;71-A:839-47.

25. Fernandez DL, Geissler WB. Treatment of displaced articular fractures of the radius. J Hand Surg [Am] 1991;16:375-84.

26. Solgaard S. Function after distal radius fracture. Acta Orthop Scand 1988;59:39-42.

27. Villar RN, Marsh D, Rushton N, Greatorex RA. Three years after Colles' fracture: a prospective review. J Bone Joint Surg [Br] 1987;69-B:635-8.

28. Kopylov P, Johnell 0, Redlund-Johnell I, Bengner U. Fractures of the distal end of the radius in young adults: a 30-year follow-up. J Hand Surg [Br] 1993;18:45-9.

29. Trumble TE, Schmitt SR, Vedder NB. Factors affecting functional outcome of displaced intra-articular distal radius fractures. J Hand Surg [Am] 1994;19:325-40.

30. Scheck M. Long-term follow-up of treatment of comminuted fractures of the distal end of the radius by transfixation with Kirschner wires and cast. J Bone Joint Surg [Am] 1962;44-A:337-51. 
31. DePalma AF. Comminuted fractures of the distal end of the radius treated by ulnar pinning. J Bone Joint Surg [Am] 1952;24-A:651-62.

32. Jenkins NH, Mintowt-Czyz WJ. Mal-union and dysfunction in Colles' fracture. J Hand Surg [Br] 1988;13:291-3.

33. Altissimi M, Antenucci R, Fiacca C, Mancini GB. Long-term results of conservative treatment of fractures of the distal radius. Clin Orthop 1986;206:202-10.

34. Young BT, Rayan GM. Outcome following nonoperative treatment of displaced distal radius fractures in low-demand patients older than 60 years. J Hand Surg [Am] 2000;25:19-28.

35. Overgaard S, Solgaard S. Osteoarthritis after Colles' fracture. Orthopaedics 1989;12:413-16

36. Mackenney PJ, McQueen MM, Elton R. Prediction of instability in distal radial fractures. J Bone Joint Surg [Am] 2006;88-A:1944-51.
37. Catalano LW 3rd, Cole RJ, Gelberman RH, et al. Displaced intra-articular fractures of the distal aspect of the radius: long-term results in young adults after open reduction and internal fixation. J Bone Joint Surg [Am] 1997;79A:1290-302

38. Smaill GB. Long-term follow-up of Colles' fracture. J Bone Joint Surg [Br] 1965;47B:80-5.

39. Zarins B. Are validated questionnaires valid? J Bone Joint Surg [Am] 2005;87A:1671-2.

40. Doornberg JN, Ring D, Fabian LM, et al. Pain dominates measurements of elbow function and health status. J Bone Joint Surg [Am] 2005:87-A:1725-31.

41. Goldfarb CA, Rudzki JR, Catalano LW, Hughes M, Borrelli J Jr. Fifteen-year outcome of displaced intra-articular fractures of the distal radius. J Hand Surg [Am] 2006;31:633-9 